Analítica 2001

\title{
A Química Analítica no Ensino Secundário
}

O ensino em Portugal pode ser visto como um leque que se abre, em que as matérias se vão complexando e aprofundando ao longo do tempo, desde o ensino básico até ao $12^{\circ}$ ano.

Nas escolas do ensino básico, os alunos começam por adquirir competências básicas no domínio da Língua Portuguesa, com a leitura e a escrita e da Matemática, com a representação dos números e as quatro operações. São iniciados no estudo da Natureza e alguns fenómenos simples naquilo a que se chama Estudo do Meio, e ainda, no conhecimento da História e Geografia de Portugal.

Quando transita para o quinto e sexto anos, o aluno alarga os seus horizontes a diferentes níveis, introduzindo-se novas disciplinas como Língua Estrangeira, Educação Física, Educação Musical, Educação Visual e Tecnológica e, no contexto da nova reforma, surge a Área de Projecto e a Educação Cívica.

Quando se passa para o sétimo, oitavo e nono anos, a História separa-se da Geografia; o estudo da natureza torna-se mais especializado e introduz-se a disciplina de Ciências Físico-Químicas.

Nos programas em vigor até 1992, os alunos no nono ano tinham oportunidade de optar por várias disciplinas, sendo uma delas a Quimicotécnia. Esta disciplina tinha continuação na Química Geral e na Química Analítica.

O ensino da Química Analitica (QA) surgia como opção no $10 .^{\circ}$ ano, tendo uma componente fortemente prática. Enquanto no décimo ano o programa incidia nos aspectos qualitativos, já no décimo primeiro ano tinha como objecto os aspectos quantitativos da análise química.

0 ensino secundário hoje tem como objectivos:

- aprofundar valores, atitudes e práticas;

- desenvolver capacidades como sejam a reflexão crítica, a observação, curiosidade científica, comunicação e cooperação, hábitos de trabalho (individual e em grupo) e espírito de iniciativa;

- proporcionar o aprofundamento de saberes - saber fazer e saber ser - e o domínio de instrumentos e de metodologias que favoreçam uma educação permanente ao longo de toda a vida;

- facultar uma formação que aproxime o jovem à comunidade e permita contribuir para a melhor solução de problemas da comunidade nacional e internacional.

Com estes objectivos, em 1992 entra em vigor a reforma do sistema educativo, dividindo-se o ensino secundário, a

figura 1

\begin{tabular}{|c|c|}
\hline CsPOVA & CsPOPE \\
\hline CURSOS TECNOLOO & S AGRUPAMENTO 1 \\
\hline CURSO TECNOLÓGI & DE QUIMICA \\
\hline - Formação Técnica & - Formaçäo Técnica \\
\hline \multicolumn{2}{|c|}{ - Formaçâo Geral } \\
\hline \multicolumn{2}{|c|}{ - Formação Específica } \\
\hline
\end{tabular}

partir do $10 .^{\circ}$ ano, em duas áreas com troncos comuns:

- os CSPOVA - Cursos Secundários Predominantemente Orientados para a Vida Activa, os Cursos Tecnológicos

- os CSPOPE - Cursos Secundários Predominantemente Orientados para o Prosseguimento de Estudos.

Um dos cursos englobados nos CSPOVA é o Curso Tecnológico de Química, o qual vem introduzir a componente de química analítica, teórica e prática, no Ensino Secundário, abrangendo um leque muito restrito de escolas e de alunos. Tal facto deve-se a vários factores, dos quais um dos mais importantes é o factor custo (envolve equipamento, manutenção e materiais com custos muito elevados). Também no que se refere a saídas profissionais convém diversificar a oferta, pelo que em cada área geográfica as escolas oferecem cursos diversos.

A criação de disciplinas de opção naquilo a que se chamou a componente técnica, vem substituir as disciplinas de Quimicotécnia, Química Analítica e Química Geral, nos CSPOPE. Tais discipli-

figura 2

\begin{tabular}{|c|} 
C. T. QUIMICA \\
FORMAÇÃO TÉCNICA \\
- BIOQUIMICA \\
- CIENCIAS DO AMBIENTE \\
- TECNOLOGIAS \\
. PRATICAS OFICINAISE LABORATORIAIS
\end{tabular}




\begin{tabular}{|l|}
\hline CSPOPE \\
FORMAÇÃO TEECNICA \\
TECNICAS LABORATORIAIS DE QUIMICA \\
- BLOCO 1 \\
- BLOCO 2 \\
- BLOCO 3 \\
\hline
\end{tabular}

figura 3

nas são actualmente as Técnicas Laboratoriais de Química leccionadas nos três anos, $10 .^{\circ}, 11 .^{\circ}$ e $12 .^{\circ}$.

A disciplina de TLQ inicia-se no bloco I com a ambientação ao laboratório e determinação de algumas propriedades características das substâncias puras, concluindo com a preparação de soluções.

CSPOPE
TÉCNICAS LABORATORIAIS DE QUIMICA
BLOCO 1
- SEGURANGCA EM LABORATORIOS DE QUIMICA
- MATERIAL DELAGORAT ORIO E SEU MANUSEAMENTO
- MEDIÇÃO EM QUIMICA
- DET ERMINAÇAO DE ALGUMAS CONSTANTES FISICO
QUIMICAS
- SOLUÇOES
- OPERAÇOES UNITARIAS

figura 4

O bloco II inicia-se com a preparação de sais, seguindo-se a identificação de alguns aniões e catiões e posteriormente o estudo dos métodos volumétricos de análise.

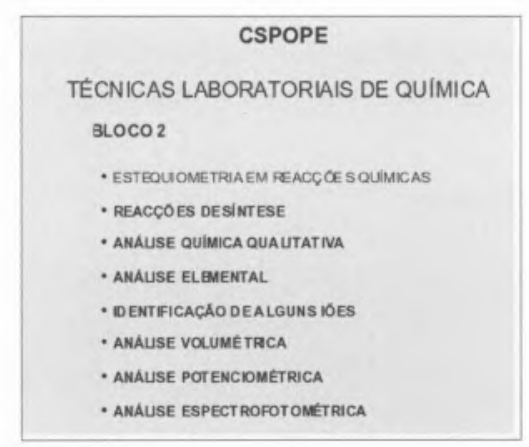

figura 5

O bloco III aplica os métodos de análise ao estudo do meio ambiente, com gran-

\begin{tabular}{|c|} 
CSPOPE \\
TÉCNICAS LABORATORIAIS DE QUIMICA \\
BLOCO 3 \\
- INTRODUÇÃO \\
OMEIOAMBIENTE \\
OUALIDADE DE VIDA \\
OUMICA NO AMBENTE \\
-AGUA \\
-AR \\
- SOLO \\
\hline
\end{tabular}

\section{figura 6}

de ênfase no estudo dos parâmetros químicos da qualidade da água.

Esta disciplina, com a duração de 3 horas semanais distribuídas na forma $2+1$ ou 3 horas seguidas, é leccionada em laboratórios apetrechados para o efeito, ou em salas de aula localizadas perto do laboratório de Química, com água corrente e saída de esgoto, permitindo deslocar o material e funcionando como uma extensão do laboratório.

O Curso Tecnológico de Química permite ao aluno adquirir saberes e competências para o exercício de uma das seguintes profissões:

- Técnico de Laboratório em Unidades Fabris;

- Auxiliar de Produção;

- Preparador de Laboratório, etc.

Ao terminar a formação do $12 .^{\circ}$ ano, o aluno adquire um diploma de estudos secundários e um certificado de formação profissional, uma vez que o curso tecnológico de química é uma formação profissionalmente qualificante, de nível III, tal como foi definido este nível em 1985 por Decisão do Conselho das Comunidades Europeias. Este nível corresponde a profissionais altamente qualificados, chefes de equipa ou técnicos intermédios.

Assim, após conclusão do ensino secundário, o aluno poderá exercer a sua actividade em:

- empresas de diversos sectores industriais;

- empresas da área da química;

- empresas da área agro-alimentar;
- laboratórios de estabelecimentos de ensino;

- ETA's (Estações de Tratamento de Águas de abastecimento) ou ETAR's (Estações de Tratamento de Águas Residuais), quer industriais quer urbanas.

Pode ainda se assim o desejar ingressar no ensino superior, universitário ou politécnico.

As aulas experimentais levam os alunos a perceberem as ciências como saberes que se constroem ao longo dos tempos, de forma a poder responder a questões específicas, colocando hipóteses, experimentando e ensaiando de novo até poder concluir.

Eliminar as disciplinas da componente técnica, sem a clara garantia que esta prática de cultura experimental se mantém, é retirar uma componente fundamental do saber. Voltamos ao ensino pelo livro, seja o livro um manual, uma revista, um $C D$ ou um site,

Considerando em conjunto o CTQ e a disciplina de Técnicas Laboratoriais de Química, um número significativo de alunos, talvez cerca de $20 \%$ dos alunos que frequentam o curso secundário, possui conhecimentos de Química Analítica.

Na disciplina de Ciências Físico-Químicas não aparece nenhum tópico que aborde temas da área da QA.

Será que, com a aplicação da nova reforma a partir do próximo ano, a situação se irá modificar?

Uma vez que as disciplinas da formação técnica irão desaparecer será que nos novos programas a componente prática tem algum peso?

Até agora uma grande percentagem de alunos do Agrupamento 1 antes de frequentar a Universidade já teve aulas práticas devido à frequência da componente técnica , ou seja está ambientado ao trabalho em laboratório; conhece o nome do material, regras de segurança, etc.

Como será no futuro? 